\title{
The generation of vibrotactile patterns on a linear array: Influences of body site, time, and presentation mode
}

\author{
ROGER W. CHOLEWIAK and AMY A. COLLINS \\ Princeton University, Princeton, New Jersey
}

\begin{abstract}
In order to provide information regarding orientation or direction, a convenient code employs vectors (lines) because they have both length and direction. Potential users of such information, encoded tactually, could include persons who are blind, as well as pilots, astronauts, and scuba divers, all of whom need to maintain spatial awareness in their respective unusual environments. In these situations, a tactile display can enhance environmental awareness. In this study, optimal parameters were explored for lines presented dynamically to the skin with vibrotactile arrays on three body sites, with veridical and saltatory presentation modes. Perceived length, straightness, spatial distribution, and smoothness were judged while the durations of the discrete taps making up the "drawn" dotted lines and the times between them were varied. The results indicate that the two modes produce equivalent sensations and that similar sets of timing parameters, within the ranges tested, result in "good" lines at each site.
\end{abstract}

In situations in which vision and/or audition are absent or are available but limited by information overload, an efficient use of the available sensory modalities might be to employ the sense of touch for the accurate perception of alerts, position, mobility, or navigation (see, e.g., Korteling \& van Emmerik, 1998). With such a system, involving spatial orientation and attitude awareness, it might be necessary to present tactile patterns in different orientations, on different body sites, for extended periods of time, and/or in the presence of distracting noise or competing stimuli from other sensory modalities. Thus, for best use, the tactile patterns employed should produce readily perceived sensations whose meanings are intuitive or at least, as Penders (1953) described, "meaningful within their situation" (p. 15). One such pattern could be a directional line, a vector. The purpose of the present experiments was to examine the parameters of linear vibrotactile patterns that would allow them to be readily appreciated. These include exploration of the body sites and presentation conditions for generating "good" vibrotactile lines, for even the simplest of linear patterns can differ greatly in salience,

Portions of this work were presented at the 36th Annual Meeting of the Psychonomic Society. The research and manuscript preparation were supported by ONR Grant N00014-95-1-0387 and NIH Grant NS04755 to Princeton University. The authors express their appreciation to Alan Goble and Christine Hakami for their contributions during the conceptualization and implementation of the project that led to these studies. In addition, Ms. Hakami contributed significantly during the periods of data collection and preliminary statistical analyses. We also express our appreciation to Carl Sherrick for his constructive comments on this manuscript. Correspondence concerning this article should be sent to R. W. Cholewiak or A. A. Collins, Cutaneous Communication Laboratory, Department of Psychology, Green Hall, Princeton University, Princeton, NJ 08544-1010 (e-mail: rcholewi@princeton.edu). depending on the method used to elaborate them (see, e.g., Langford, Hall, \& Monty, 1973).

Different applications may require the use of different body sites for a tactile display. Indeed, although the finger and hand have greater tactile sensitivity (see, e.g., Weinstein, 1968), for many applications the preferred site may be the back or the forearm, in order to free the hands for tasks requiring dexterity. For example, recent demonstrations have shown that simple linear tactile arrays fitted to the forearm or the abdomen can be used effectively to present flight information, such as airspeed and attitude, in fixed- and rotary-wing aircraft (Naval Aerospace Medical Research Laboratories, 1996; Raj, Suri, Braithwaite, \& Rupert, 1998), while the pilot's hands are left free to operate controls. Similarly, a vibrotactile aid for persons who are deaf, the Tactaid-7, employs a linear array of seven tactors with recommended presentation sites on the chest or the nape of the neck (Robbins, Hesketh, \& Bivins, 1993; Weisenberger \& Percy, 1995). These placements permit the user to engage in other activities with freedom of movement, but with the benefit of the display. In contrast, for sedentary activities, the fingers are acceptable as presentation sites (e.g., systems that enable persons who are blind to read printed text).

As with many aspects of training and learning, it is often assumed that sensations on one body site will be apprehended in the same manner across other sites. However, this equivalence must be established. An exploration of several sites has particular significance when one considers that different loci have different types and densities of receptors (Bolanowski, Gescheider, \& Verrillo, 1994; Bolanowski, Gescheider, Verrillo, \& Checkosky, 1988; Darian-Smith, 1982; Vallbo \& Johansson, 1978). The receptor populations found over the surface of the skin can vary considerably in their sensitivity to tactile 
stimuli (Johnson \& Hsiao, 1992; Stevens, 1990; Verrillo, 1974; Weinstein, 1968; Wilska, 1954). But most germane to the present discussion, sites such as the finger, forearm, and back, with their unique underlying receptor populations, have very different responses to the spatial aspects of tactile stimuli. Two-point threshold and error of localization for taps, commonly accepted indices of the relative acuity of the skin, have been found to vary considerably over the surface of the body (e.g., Stevens \& Choo, 1996; Weinstein, 1968; but see Johnson, Van Boven, \& Hsiao, 1993). One implication from these findings is that the density of tactile displays (how close contactors are to one another) must be related to the spatial resolution of the skin site to which they are fitted, if the spatial information in a pattern is to be equally available at each site (Cholewiak \& Collins, 1991, 1995; Daley \& Singer, 1975; Greenspan \& Bolanowski, 1996).

In fact, little is known about the similarity in pattern perception and processing across body sites even when allowances are made for differences in spatial acuity among sites. In the few studies that have examined these issues, both differences and commonalities in performance have been found among such sites as the finger, forearm, and thigh when the perception of tactile extent (Cholewiak, 1986, 1999), pattern "communality" (Cholewiak \& Collins, 1995), pattern identification and discrimination (Cholewiak \& Craig, 1984), and cutaneous saltation (Geldard \& Sherrick, 1983) were measured, using vibrotactile arrays. In only three studies that we are aware of (Cholewiak \& Collins, 1988; Cholewiak \& Craig, 1984; Engelmann \& Rosov, 1975) have the perceptions of the same set of patterns been examined on several body sites to evaluate whether the percepts are isomorphic. In these cases, important distinctions were found. Mirroring the results found for two-point threshold and error of localization for taps, a major difference among sites appears to be related to the amount of spatial detail perceived in spatially complex patterns: Detail can be lost or shape distorted when the same pattern is presented to one site as opposed to another. Additional well-controlled studies in which the equivalence among different body sites is examined are obviously needed to improve device designs, as well as to allow for greater flexibility regarding placement. This need prompted the study of the three sites in the research to be described here.

As was mentioned earlier, the aim of these studies was to create an intuitive directional tactile vector presented on a simple linear array. Given current technology and practical demands, a vibrotactile display is the best choice because of its flexibility and intensitive range. There are a number of ways in which spatiotemporal patterns can be elaborated on such arrays (Craig, 1980; Craig \& Sherrick, 1982; Loomis, 1974; Sherrick \& Cholewiak, 1977). Two presentation modes were chosen to produce a sensation of a discontinuous or dotted line drawn on the skin as activity apparently "hops" from locus to locus. The first (veridical) mode requires that all of the elements that make up a line be activated in sequence (e.g., Gonzales,
1996). The second mode is saltation, a tactile illusion of displacement. Discovered and studied extensively in the Cutaneous Communication Laboratory (Geldard, 1975; Geldard \& Sherrick, 1972), saltation occurs in vision, audition, and touch (see, e.g., Cholewiak, 1976, 1986, 1999). It is a phenomenon in which a series of stimuli at one point appears to be mislocalized seriatim, owing to the presence of one or more stimuli at a second place, presented close to the first ones spatially and temporally. Those mislocalizations are particularly vivid and well ordered and form a line connecting the two generating loci. When saltation occurs, the series of taps at only a few loci can appear to distribute themselves more or less evenly over the intertactor space, producing the sensation of a finely grained drawn dotted line. Saltation is distinguished from the more familiar illusion of beta movement, commonly called Phi, in which the sensation that emerges most is one of movement rather than displacement and for which the spatial and temporal relationships, particularly in vision, are somewhat different (Graham, 1951, 1965). In these experiments, it is expected that the percept of similar lines with the same number of perceived loci will be produced with these two methods even though the two differ in the number of generating sites (tactors) involved: Because saltation produces illusory percepts of loci between active tactors, fewer tactors would be needed to span an extent than would be needed for the same extent with the veridical mode.

The specific question to be addressed with the present experiments is the determination of the optimal timing parameters for presentation of a directional vector on a linear vibrotactile array. The appearance of either apparent movement or saltation in any sensory modality is known to depend on the burst durations (BDs) and interburst intervals (IBIs) in the sequence of activity over the series of separate loci (Exner, 1875; Geldard, 1975; Geldard \& Sherrick, 1983; Graham, 1951, 1965; Kenkel, 1913; Kirman, 1974, 1975; Penders, 1953; Wertheimer, 1912). In 1915, Korte proposed a series of laws to describe the interrelations among the relevant stimulus dimensions in vision. Of these, his fourth law, concerning beta movement, is most relevant here: Over a limited range of stimulus conditions, in order for the report of optimal movement to be maintained, BD must be decreased as IBI increases, with stimulus intensity and spatial extent held constant. Neuhaus's (1930) work extended these notions by testing several stimulus conditions over ranges sufficiently wide to more completely describe the stimulus duration, interstimulus interval, spatial extent, and stimulus intensity required to produce the optimal sensation of a flash of light smoothly moving across a space from one locus to another. These parameters were found to have a multisensory generality when Sherrick and Rogers (1966) found that the same functional relationship existed between stimulus BD and interstimulus interval for optimal apparent movement when vibrotactile and electrotactile stimuli were presented over the same temporal range of 3-400 msec. Geldard and his associ- 
ates (Cholewiak, 1976; Geldard, 1975; Geldard \& Sherrick, 1983) found the quality of the saltatory illusion to vary over a similar range of IBIs. The experiments to be described here explored the temporal parameters of vibrotactile patterns that were skewed toward the briefer range to provide for more rapid information transfer in a tactile communication system, because at a practical level, a system that employed patterns with multiple elements having durations of $300-400 \mathrm{msec}$ each would be ponderous.

In these experiments, BD and IBI were varied on several body sites (finger, arm, back). Comparisons were also made across presentation mode (veridical and saltatory) to define the parameters that generate the best vector on the skin. Observers were first asked to judge a number of different qualities of lines drawn with the two modes when a single pattern was presented (Experiment 1). Second, in two-alternative forced-choice pairedcomparison paradigms, subjects were asked to (1) discriminate between "lines" presented with the same BD and IBI but with different presentation modes and (2) judge which member of these pairs was the "better line" (Experiment 2 ). In these cases, the observers directly compared the sensations produced by the two modes revealing their level of similarity.

\section{GENERAL METHOD}

\section{Subjects}

The subject population was drawn from students at the university, as well as members of the community and laboratory staff. Informed consent was obtained from all the subjects prior to testing, and nonstaff were paid for their participation at university-approved rates for human subjects.

\section{Body Sites}

These studies were conducted with arrays touching the distal pad of the left index finger, the left volar (flexor) surface of the forearm, and vertically on the left lower aspect of the back (the fleshy area just above the waist). These sites are representatives of the two major skin types, glabrous and hairy skin, which differ in receptor type, density, biomechanical properties, and sensitivities, which range, for example, from a 2-mm two-point threshold on the finger to $40 \mathrm{~mm}$ or so on the back (Weinstein, 1968). The first two sites have been examined in a number of studies of tactile pattern-processing performance (see, e g., Brooks, Frost, Mason, \& Gibson, 1986; Cholewiak \& Craig, 1984; Craig \& Sherrick, 1982; Stevens \& Choo, 1996; Weisenberger \& Percy, 1995), whereas the abdomen, although less well explored (but see Oller \& Eilers, 1987; Saunders, 1974; Sparks, 1979), is a likely location for presentation of spatial orientation information (Mead, Rupert, \& Jarmul, 1994; Naval Aerospace Medical Research Laboratories, 1996; Rupert, Guedry, \& Reschke, 1993).

\section{Vibrotactile Arrays}

A tactile pattern will be defined here as a temporal display of information on a line of vibrators touching the skin. Two arrays, shown in Figure 1, were used in these studies: The first is the array from the Optacon, a reading machine for blind persons, which is used to present tactile patterns to the finger. It consists of 144 pins that can vibrate, arranged in a matrix of six columns that are $2.54 \mathrm{~mm}$ apart and 24 rows separated by $1.27 \mathrm{~mm}$ each. Only the central two columns and Rows 2-15 from the top were used to generate the linear stimuli. The fingerpad was placed on the surface of the finger rest, and the hand was stabilized with a light sandbag to retain proper contact. The second display, the Princeton Linear Array, is a custombuilt system consisting of seven vibrators (tactors) using piezoceramic Bimorph Benders as drivers, with 7-mm diameter contactors, mounted on a broad flexible Velcro support band. This array, which is wearable and can be fitted to a number of body sites, was used here on the forearm and the lower back. To ensure proper placement of either array with reference to the body site of interest, alignment procedures were followed in each case. For the Optacon, an inverted
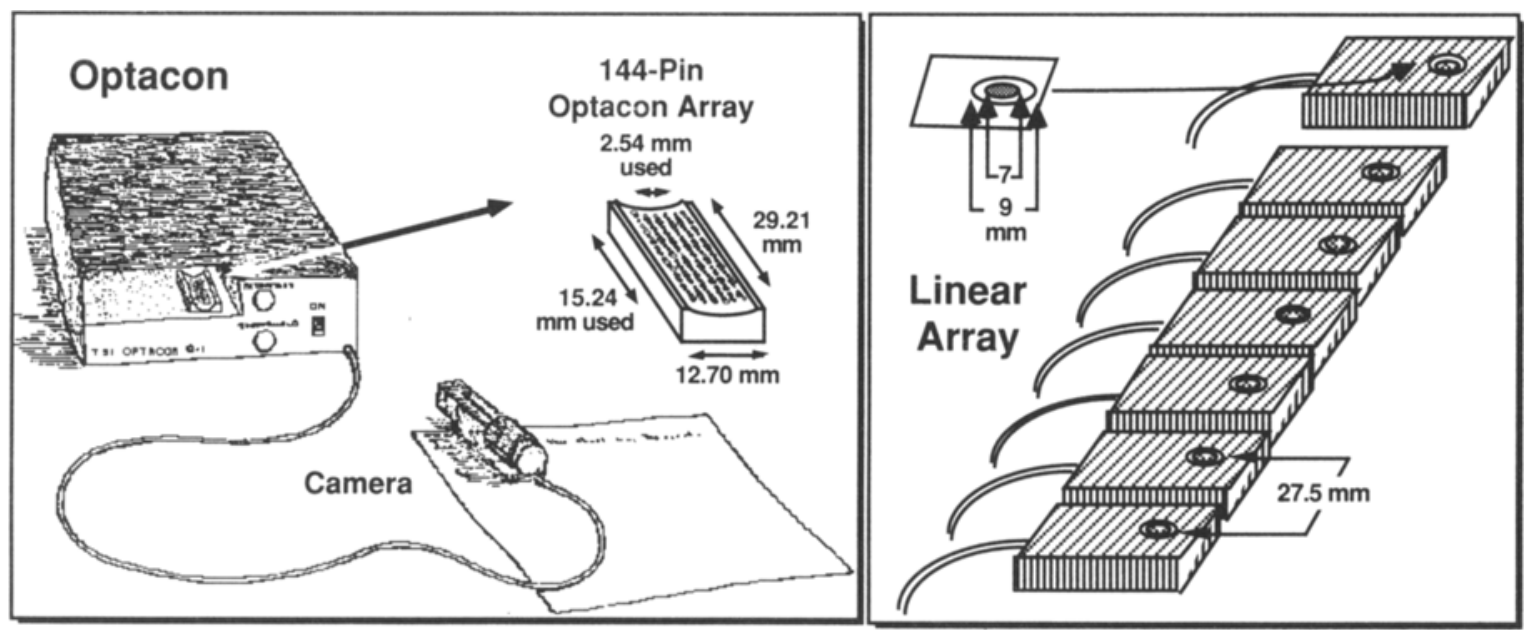

Figure 1. The Optacon, a direct print-to-tactile pattern converter, is shown on the left. Camera images are displayed as pointfor-point vibrating patterns on the 6-column $\times 24$-row tactile array. In this study, a computer replaced the camera to define the spatial layout and temporal parameters to be displayed, and only a 2-column $x$ 14-row subset of pins was used. On the right is the Princeton Linear Array of seven enclosed and independent piezoceramic benders (tactors) that vibrate the skin, with 7mm contactors that protrude through holes in each case. The spatiotemporal parameters of the pattern of activation on the Princeton Linear Array were also computer controlled. 
U-shaped pattern, produced by driving the outer columns and the top two rows, was presented on the array prior to testing. The observers were asked to position the finger so that this pattern was felt to enclose the fingertip. For the Princeton Linear Array, each tactor was activated singly in a random sequence, and the observers were instructed to indicate whether the activity had been felt. Both displays were interfaced with computers that controlled the spatial and temporal parameters of pattern generation, as well as collecting, storing, and analyzing the data.

\section{Stimuli}

On the fingertip, each of the seven loci was defined by four points, to ensure sufficient perceived intensity, in a $2 \times 2$ arrangement of neighboring pins driven simultaneously on the Optacon array. The resulting physical separation between the centers of adjacent loci was $2.54 \mathrm{~mm}$. When the site to be examined was the forearm or the back, the set of potential loci consisted of the seven individual tactors in the Princeton Linear Array, with center-to-center tactor separations of $27.5 \mathrm{~mm}$. Consequently, the extent of the display was $15.24 \mathrm{~mm}$ along the length of the fingertip and $165 \mathrm{~mm}$ on the arm and back. Stimulus patterns consisted of bursts of vibration presented to each or to a subset of the seven elements on each array. Specifically, tactors were activated sequentially, so as to "draw" a line on the skin, with a computerized system that is capa- ble of varying stimulus parameters between pattern presentations. A $230-\mathrm{Hz}$ stimulus frequency was employed because the skin is quite sensitive to frequencies in this range, particularly with larger contactor sizes, such as those used in the Princeton Linear Array. Furthermore, the Optacon array is hard-wired to be driven at this frequency. Because the Optacon contactors touch the skin only for around $0.8 \mathrm{msec}$ out of each 4.35 -msec cycle (Bliss, Katcher, Rogers, \& Shepard, 1970, p. 60, Figure 4), the driving waveform might best be characterized as being 230 pulses per second. Stimulus amplitudes were set to comfortable, readily palpable levels (around 14-20 dB SL).

\section{Presentation Modes}

In these experiments, two display modes were used. These differed in the number of active loci. The first, the veridical mode, effectively "drew" a dotted line on the skin by presenting a simple series of bursts of vibration at each of the seven loci in sequence. In the second, the saltatory mode, only three locations (the first, fourth, and seventh) were activated. These three loci were $7.6 \mathrm{~mm}$ apart on the fingertip and $90 \mathrm{~mm}$ apart on the arm and back. Furthermore, when the saltatory mode was used, instead of presenting one vibratory burst per locus, there were three bursts on the first location, three on the fourth, and one on the seventh. Although saltation has been studied with as few as two loci, the vividness of such illusions

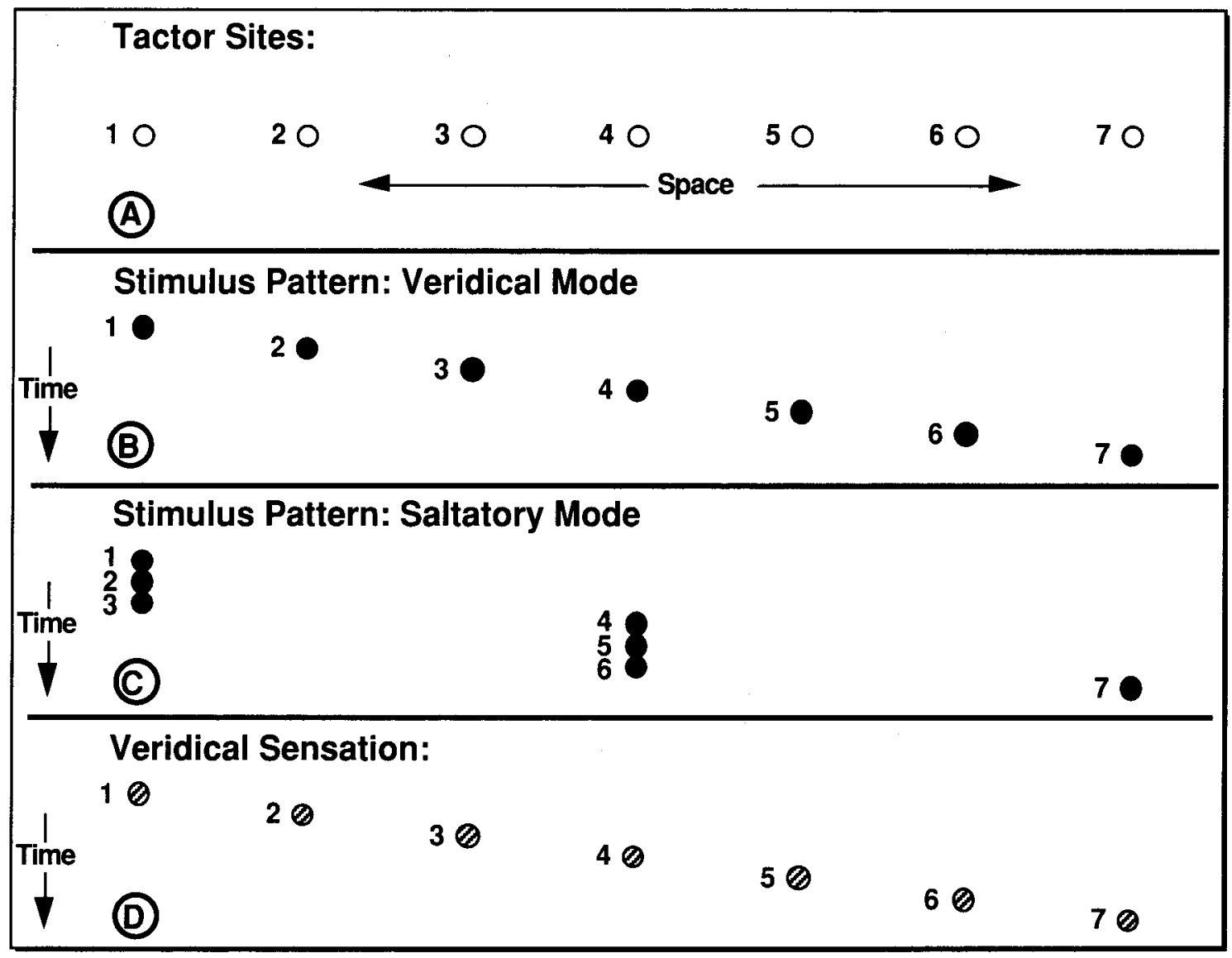

Figure 2. Visual representations of the vibrotactile spatiotemporal patterns. Seven sites, shown in (A), were aligned along the finger (with the Optacon), along the arm (Princeton Linear Array), or down the back (Princeton Linear Array). In the veridical presentation mode, bursts of vibration were presented sequentially along all seven sites (B). In the saltatory mode, the seven bursts occurred at only three sites $(C)$. In both cases, interburst interval was constant over the series of bursts. In a typical veridical presentation (B), one feels a series of stimuli marching along the skin over time (D). Given appropriate timing parameters, saltatory presentations (C) would also feel like this series (D). 
improves with additional tactors (see, e.g., Geldard, 1975; Kirman, 1975). The spatial structures were different in the patterns presented in these two modes, but the design ensures corresponding temporal parameters in the two presentation modes, including the same number of bursts in both. It should be noted that the observers were not told how many of the loci would be active in any presentation. In fact, the Princeton Linear Array was completely covered by a $100 \%$ cotton knit material, so it was not obvious how many potential sites were in the array. Figure 2 illustrates the spatiotemporal display modes, including the physical arrangement of the active tactors and a representation of one possible perceptual experience. When the saltatory mode is presented, the percepts can range from that shown in panel D, with sensations equidistant from one another, or can duplicate the stimulus arrangement in which vibration is felt only at the three original generation sites (panel C). In saltation, the parameter that controls the perceived spatial layout is, to a large degree, the temporal separation between bursts of vibration (Cholewiak, 1999). For these spatial separations, long ( $>300 \mathrm{msec}$ ) temporal separations result in stimuli felt to occur at their sites of origin, whereas for shorter interstimulus intervals stimuli come to be perceived as spatially distributed (Cholewiak, 1976; Geldard, 1975; Geldard \& Sherrick, 1986).

\section{Temporal Parameters}

There were seven different levels for the temporal parameters. The values for the BDs and the IBIs were 4, 9, 17, 26, 35, 70, and $139 \mathrm{msec}$. These durations were equivalent to $1,2,4,6,8,16$, and 32 cycles of the $230-\mathrm{Hz}$ ( $4.35-\mathrm{msec}$ period) driving signal. Over these combinations of BDs and IBIs, stimulus onset asynchronies range from 9 to $278 \mathrm{msec}$. Table 1 illustrates the range of durations and the resulting apparent velocities of movement available for the combinations of timing conditions and the distances available on the two different arrays. Note that the velocities on the two arrays overlap for only a few cells. Obviously, not every possible set of con- ditions was tested. The combinations of body sites, spatial separations, and temporal dimensions that were employed, however, sample those that could be practically used in a tactile communication system. For example, total pattern durations longer than those used here would slow information transfer in most cases, severely limiting the usefulness of such a system.

\section{Apparatus}

Responses were made by the subject on a keyboard encoded with labels to indicate the response (from 1 to 10 or either yes or no for Experiment 1, S and D or 1 and 2 for Experiment 2), whereas taskrelated event information was presented to the subject on an alphanumeric display. Filtered white noise was provided through circumaural headphones to mask any environmental noises or cues from the stimulators. Skin temperature at the site was monitored and maintained within the range of $30^{\circ}-35^{\circ} \mathrm{C}$. In the first part of Experiment 2, auditory feedback was provided in the form of tone pips indicating correct (high pitch) or incorrect (low pitch) responses.

\section{EXPERIMENT 1}

In this study, the observers judged the "goodness" of a dotted line drawn with successive taps on a vibrotactile array. The duration of the vibratory bursts and the temporal intervals between them were varied, as was the presentation mode (i.e., veridical and saltatory). The intention was to determine the most efficient scheme for generating the "best" vector on several body sites. For example, it is known that a physically straight line should not be drawn too slowly on the skin, lest a circuitous route be perceived. Langford et al. (1973) indicate that, at rates of around $2 \mathrm{~cm} / \mathrm{sec}$, a line drawn on the skin ap-

Table 1

Durations (in Milliseconds) and Velocities for Sultatory and Veridical Stimuli

\begin{tabular}{|c|c|c|c|c|c|c|c|}
\hline \multirow[b]{2}{*}{ Burst Duration } & \multicolumn{7}{|c|}{ Interburst Interval } \\
\hline & 4.35 & 8.7 & 17.4 & 26.1 & 34.8 & 69.6 & 139.2 \\
\hline \multicolumn{8}{|c|}{ Total Stimulus Duration } \\
\hline 4.4 & 56.6 & 82.7 & 134.9 & 187.1 & 239.3 & 448.1 & 865.7 \\
\hline 8.7 & 87.0 & 113.1 & 165.3 & 217.5 & 269.7 & 478.5 & 896.1 \\
\hline 17.4 & 147.9 & 174.0 & 226.2 & 278.4 & 330.6 & 539.4 & 957.0 \\
\hline 26.1 & 208.8 & 234.9 & 287.1 & 339.3 & 391.5 & 600.3 & $1,017.9$ \\
\hline 34.8 & 269.7 & 295.8 & 348.0 & 400.2 & 452.4 & 661.2 & $1,078.8$ \\
\hline 69.6 & 513.3 & 539.4 & 591.6 & 643.8 & 696.0 & 904.8 & $1,322.4$ \\
\hline 139.2 & $1,000.5$ & $1,026.6$ & $1,078.8$ & $1,131.0$ & $1,183.2$ & $1,392.0$ & $1,809.6$ \\
\hline \multicolumn{8}{|c|}{ Velocity on $1.5-\mathrm{cm}$ Optacon $(\mathrm{cm} / \mathrm{sec})$} \\
\hline 4.4 & $26.95^{*}$ & $18.44^{*}$ & 11.30 & 8.15 & 6.37 & 3.40 & 1.76 \\
\hline 8.7 & $17.52^{*}$ & $13.47^{*}$ & 9.22 & 7.01 & 5.65 & 3.18 & 1.70 \\
\hline 17.4 & $10.30^{*}$ & $8.76^{*}$ & 6.74 & 5.47 & 4.61 & 2.83 & 1.59 \\
\hline 26.1 & 7.30 & 6.49 & 5.31 & 4.49 & 3.89 & 2.54 & 1.50 \\
\hline 34.8 & 5.65 & 5.15 & 4.38 & 3.81 & 3.37 & 2.30 & 1.41 \\
\hline 69.6 & 2.97 & 2.83 & 2.58 & 2.37 & 2.19 & 1.68 & 1.15 \\
\hline 139.2 & 1.52 & 1.48 & 1.41 & 1.35 & 1.29 & 1.09 & 0.84 \\
\hline \multicolumn{8}{|c|}{ Velocity on $16.5-\mathrm{cm}$ Linear Array $(\mathrm{cm} / \mathrm{sec})$} \\
\hline 4.4 & 291.78 & 199.64 & 122.36 & 88.21 & 68.97 & 36.83 & 19.06 \\
\hline 8.7 & 189.66 & 145.89 & 99.82 & 75.86 & 61.18 & 34.48 & 18.41 \\
\hline 17.4 & 111.56 & 94.83 & 72.94 & 59.27 & 49.91 & 30.59 & 17.24 \\
\hline 26.1 & 79.02 & 70.24 & 57.47 & 48.63 & 42.15 & 27.49 & 16.21 \\
\hline 34.8 & 61.18 & 55.78 & 47.41 & 41.23 & 36.47 & $24.95^{*}$ & $15.29^{*}$ \\
\hline 69.6 & 32.14 & 30.59 & 27.89 & 25.63 & 23.71 & $18.24^{*}$ & $12.48^{*}$ \\
\hline 139.2 & 16.49 & 16.07 & 15.29 & 14.59 & 13.95 & $11.85^{*}$ & $9.12^{*}$ \\
\hline
\end{tabular}

*Only for these conditions do the velocities overlap on the two array sizes. 
pears to wander; at $14 \mathrm{~cm} / \mathrm{sec}$ it is straight. On the other hand, if the velocity is too great, a compression in overall extent may be perceived (Whitsel et al., 1986), and minute changes in length of static patterns are readily detected (see, e.g., Schneider, Hughes, Epstein, \& Bach-yRita, 1986). The influence of velocity on judgments of apparent motion can be substantial (Strybel, Span, \& Witty, 1998) and will be discussed later. Furthermore, directional acuity, a gauge of the resolving power of the sensory system, is an additional factor that may vary with presentation parameters over body sites (Costanzo \& Gardner, 1980; Essick, 1991; Gardner \& Palmer, 1990; Gardner \& Sklar, 1994) and is important in sequential pattern processing. Finally, the similarity of the effects of timing parameters on lines drawn in the two modes was examined.

The description of an optimal stimulus in situations such as this has always been subjective. For example, subjects in an apparent-movement study by Sherrick and Rogers (1966) were instructed to adjust the duration and interval between pairs of vibratory bursts presented to the skin so as to produce the "best movement," defined as "the longest uninterrupted feeling of movement between the first stimulus site and the second." The interest in the experiments to be described here was not specifically to produce the "best movement." Rather, the focus was on the "best line," and this description was decomposed into a number of constituent qualities. By definition, a vector should be straight, extend from point $a$ to point $b$, and have an estimable extent and a clearly defined direction of movement. A number of other qualities were considered, generated by informal observation by the laboratory staff (as in Hollins, Faldowski, Rao, \& Young, 1993). They included temporal regularity, spatial distribution, smoothness, width, and intensity. These qualities were generated on the basis that they might have some potential utility for (1) disclosing differences between the two presentation modes and (2) encoding other types of information. For example, when the saltatory mode fails (because the spatial or temporal parameters are exceeded), the individual sensations cease to be well distributed over the display surface (Geldard \& Sherrick, 1983). Thus, gaps appear in the distribution of illusory loci that would be reflected in judgments of spatial distribution. In addition, the appearance of such gaps would allow presentations in this mode to be readily discriminated from those presented in the veridical mode. In displayencoding schemes intended to provide environmental information including direction, orientation, or location, the line qualities of length or direction are intuitively useful. Thus, it would be important to discover how these qualities vary with changes in the timing parameters. After extended pilot testing, the qualities of direction, temporal regularity, width, and intensity were dropped from further consideration. Observers were always able to distinguish the direction in which the lines were."drawn" with the spatiotemporal conditions to be employed and expressed high degrees of confidence in their judgments. The remaining three were eliminated because they did not vary systematically over the $\mathrm{BD} \times \mathrm{IBI}$ space defined here. The qualities of smoothness and spatial distribution were retained, along with the given vector qualities of length and straightness.

\section{Method}

Subjects. An attempt was made to counterbalance the order in which the three sites were tested over the subject population. Unexpected attrition over the extended series of sessions resulted in different numbers of observers represented in the data for each site. The numbers of subjects who judged lines presented to the finger, arm, and back were 9 ( 5 females, 4 males), 10 ( 9 females, 1 male), and 6 ( 5 females, 1 male), respectively.

Procedure. The subjects were presented with vibrotactile lines generated with the apparatus and parameters described in the General Method section and were required to judge the qualities of perceived length, smoothness, spatial distribution, and straightness. There were six sessions randomly ordered and counterbalanced over observers - one for each combination of body site (finger, arm, or back) and presentation mode (veridical or saltatory). Within each session, the four qualities were randomly ordered and judged in separate blocks of trials. At the beginning of each block, subjects were read an extended description for the particular quality to be judged in that series, in order to minimize variability in interpretation among observers. The criteria that were described include the following.

Length. The observer was asked to judge how much of the length of the body site the sensation covered. To provide a frame of reference for the finger, he or she was told to imagine the length of the finger pad from the fingertip to the first crease as the longest line possible. In the case of the arm or back, he or she was to regard the width of the cloth cover on the linear array $(170 \mathrm{~mm})$ as the longest possible stimulus.

Smoothness. The question raised for this quality was whether the apparent movement seemed smooth or coarse. If it felt as though there were seven distinct events in different locations, it was to be regarded as a choppy sensation, whereas if it seemed to be a unitary event, it was to be reported as smooth.

Spatial distribution. The observer was asked to note how well distributed the sensation felt. $\mathrm{He}$ or she was asked to consider whether all seven bursts seemed to be equally distant from one another spatially or seemed to be concentrated in only a few locations or otherwise irregularly spaced along the extent of the display. The subjects were cautioned that a full range of sensations between these options would be possible and that their ratings should reflect this lower degree of regularity.

Straightness. Each observer was asked to consider whether or not the stimulus felt straight. As alternatives to a straight line, he or she was provided with drawings and descriptions of lines that zigzagged, were bent, strayed to one side or another, or curved away from a straight path and was asked to imagine how those would feel.

When the veridical mode was tested, all of the 49 possible combinations of BD and IBI were presented within each block, one for each $\mathrm{BD} \times \mathrm{IBI}$ combination. In the case of the saltatory mode, the same conditions applied when the back was the test site. When this mode was presented to the finger and forearm, however, the ranges of temporal parameters were reduced (BD, 4-35 msec; IBI, 4-70 msec) for two reasons. Both data in the literature (e.g., Geldard \& Sherrick, 1983) and pilot testing suggested that saltation deteriorates significantly for the 70- and 139-msec BDs and the 139-msec IBIs on these two sites. Given these findings, it was deemed more efficient 
not to test parameters that would have produced markedly "poor" lines. Consequently, only 30 combinations were examined in each block of saltatory trials. The ordering of temporal conditions was randomized within each of the trial blocks. To allow for examination of possible interactions of direction with the perception of other qualities, lines were generated within a block in both directions ("up," or proximodistally, and "down," or distoproximally).

At the beginning of each trial, the name of the quality being judged was printed on the visual display. With a keystroke, the observer initiated the trial that consisted of a brief $(700-\mathrm{msec})$ preparatory delay and the presentation of a single series of bursts on the array. After the stimulus was presented, the subjects reported their judgment with a keystroke. Depending on the quality to be judged in a block of trials, the subjects were instructed to indicate the shortest, most spatially irregular, or roughest sensation possible, by pressing the leftmost key on the keyboard (labeled 1). To indicate the longest, smoothest, or most spatially regular stimulus possible, they were to respond with the rightmost key on the scale (the $10 \mathrm{key}$ ). In these cases, the subjects were cautioned that they often would feel sensations that fell somewhere between the ideal extremes. When the straightness of the lines was to be judged, only two keys were usedone labeled yes, to indicate the presence of a straight line, and a second labeled no, to indicate a stimulus that was not straight. It should be noted that these data were transformed into the proportions of re- sponses indicating that sensations were felt as straight or as not straight, so that they could be plotted on the 1-10 scale in the same manner as the other qualities.

\section{Results}

Mean quality judgments were calculated for each stimulus condition. These fell into 48 data sets distinguished by site (finger, forearm, or back), stimulus generation mode (veridical or saltatory), direction (proximodistally or distoproximally), and the four qualities to be judged. Repeated measures analyses of variance (ANOVAs) indicated that in only 3 of the 48 data sets was there a significant main effect of direction [finger, veridical, smoothness: $F(1,13)=9.656, p<.01$; back, saltatory, smoothness: $F(1,5)=37.456, p<.01$; and back, veridical, length: $F(1,5)=13.699, p<.05]$. In these cases, the sensation was smoother or longer, respectively, when presented in the upward direction. However, in each case, the magnitude of the effect was less than 0.5 rating unit. Although they reached statistical significance, these differences are marginally meaningful in the
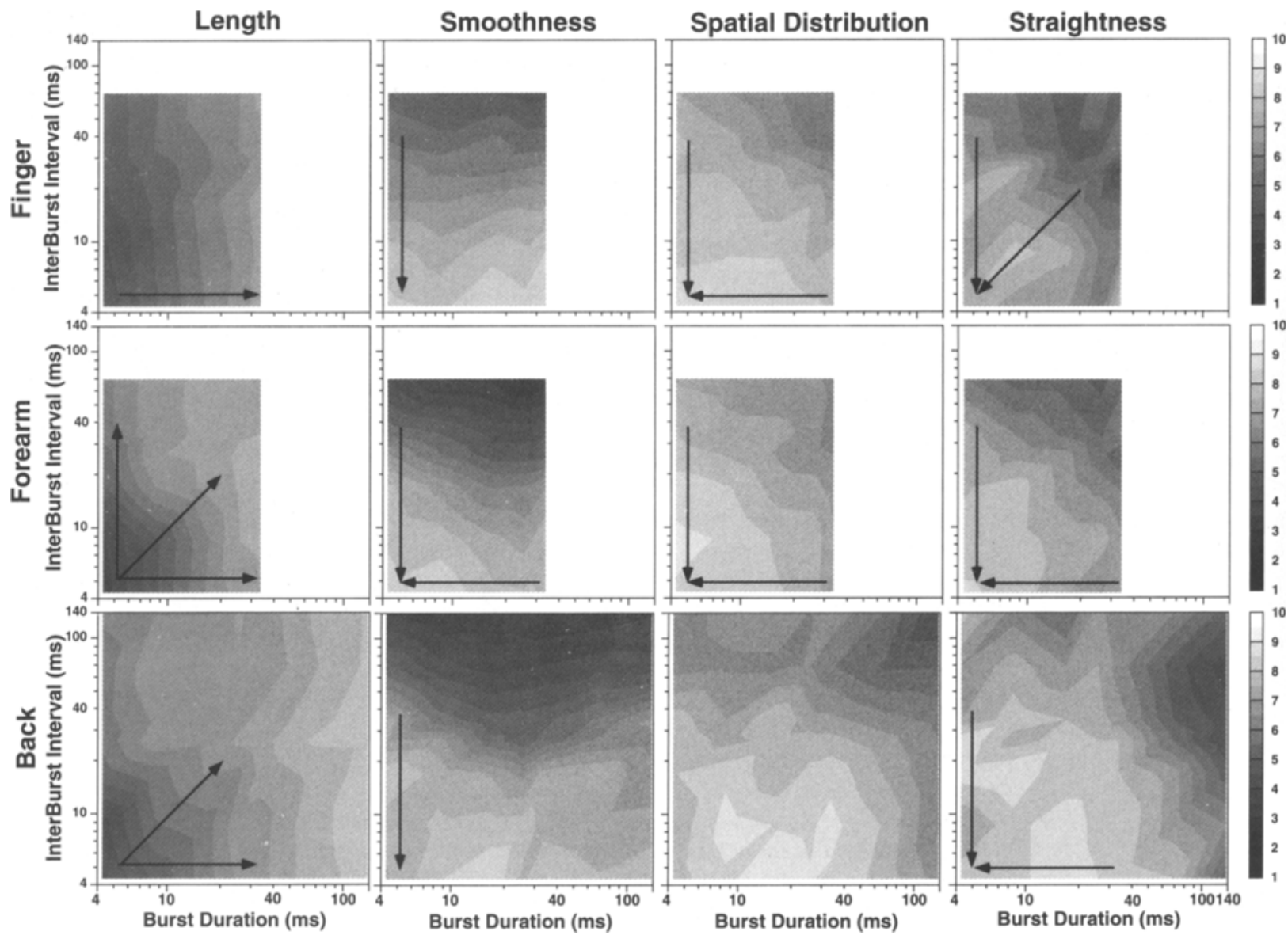

Figure 3. Judgment spaces for saltatory presentations for each site (finger, forearm, and back) and quality (length, smoothness, regularity, and straightness). Within each space, mean ratings for all the tested combinations of burst duration and interburst interval are indicated by shading. Lighter areas represent sensations that were longer, smoother, more spatially distributed, or straighter, keyed to the scales on the right. Horizontal or vertical arrows indicate statistically significant main effects of these parameters, whereas the diagonal lines represent the existence of a significant interaction. These statistics are shown in Table 2. 

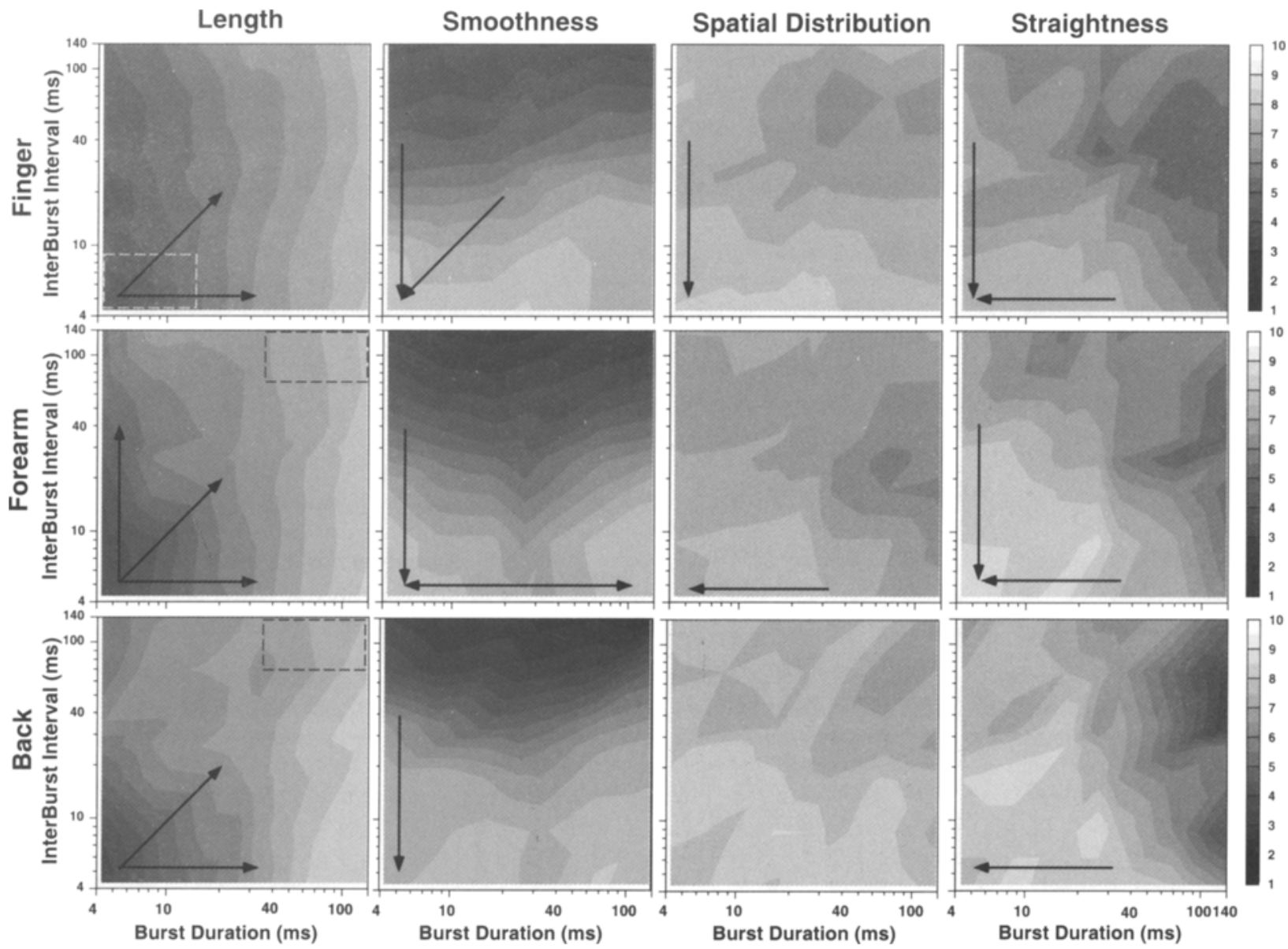

Figure 4. Judgment spaces for veridical presentations for each site and quality. Except for mode, these data are plotted as in Figure 3, with mean ratings for all tested combinations of burst duration and interburst interval indicated by shading. The lighter the region, the longer, smoother, more spatially distributed, or straighter were the sensations. Horizontal or vertical arrows indicate statistically significant main effects, whereas the diagonal lines represent the existence of a significant interaction. These statistics are shown in Table 2. The dashed rectangles in the length data sets indicate regions in which the velocities of the stimuli presented on the Optacon and the Princeton Linear Arrays overlap.

context of a 10-point scale, so for all succeeding analyses data were collapsed over presentation direction. Figures 3 and 4 show $x-y-z$ contours of the mean ratings on the $1-10$ scale for each condition as a function of BD and IBI.

Visual inspection of Figures 3 and 4 reveals that the patterns of judgments show unique responses to $\mathrm{BD}$ and IBI as a function of the quality to be rated. Furthermore, the patterns of ratings for each quality are remarkably similar across sites. These correspondences are particularly apparent within a presentation mode but are seen between modes as well. Note that the patterns of response produced by the limited range of stimuli shown in Figure 3 for the saltatory mode on the finger and arm are virtually identical to equivalent response areas generated within the context of expanded temporal ranges used on the back or for the veridical response mode (regions shown in Figure 4). This suggests that range or context effects within a condition do not play an important role in these judg- ments. These observations are supported by the results of repeated measures ANOVAs, shown in Table 2. A number of significant main effects of BD (graphically represented by horizontal arrows in Figures 3 and 4) and IBI (vertical arrows) were found. In several cases, BD $\times$ IBI interactions were also significant, as is indicated by the arrows at an angle. Again, the patterns of effects across the two modes of presentation are similar enough to suggest that the sensations produced by the two are affected by temporal parameters in the same ways. Even the rating levels across the different qualities for the two modes are alike. Indeed, in only one case (length on the forearm) was there found a significant main effect of mode $[F(1,9)=$ $11.174, p<.01]$. Veridical patterns, over the set of common BD and IBI conditions, were judged to be slightly shorter than saltatory patterns. Again, as with the effects of direction, the magnitude of this effect was less than a single rating unit in size. A two-way interaction was found between mode and $\mathrm{BD}$ on the forearm for spatial distri- 


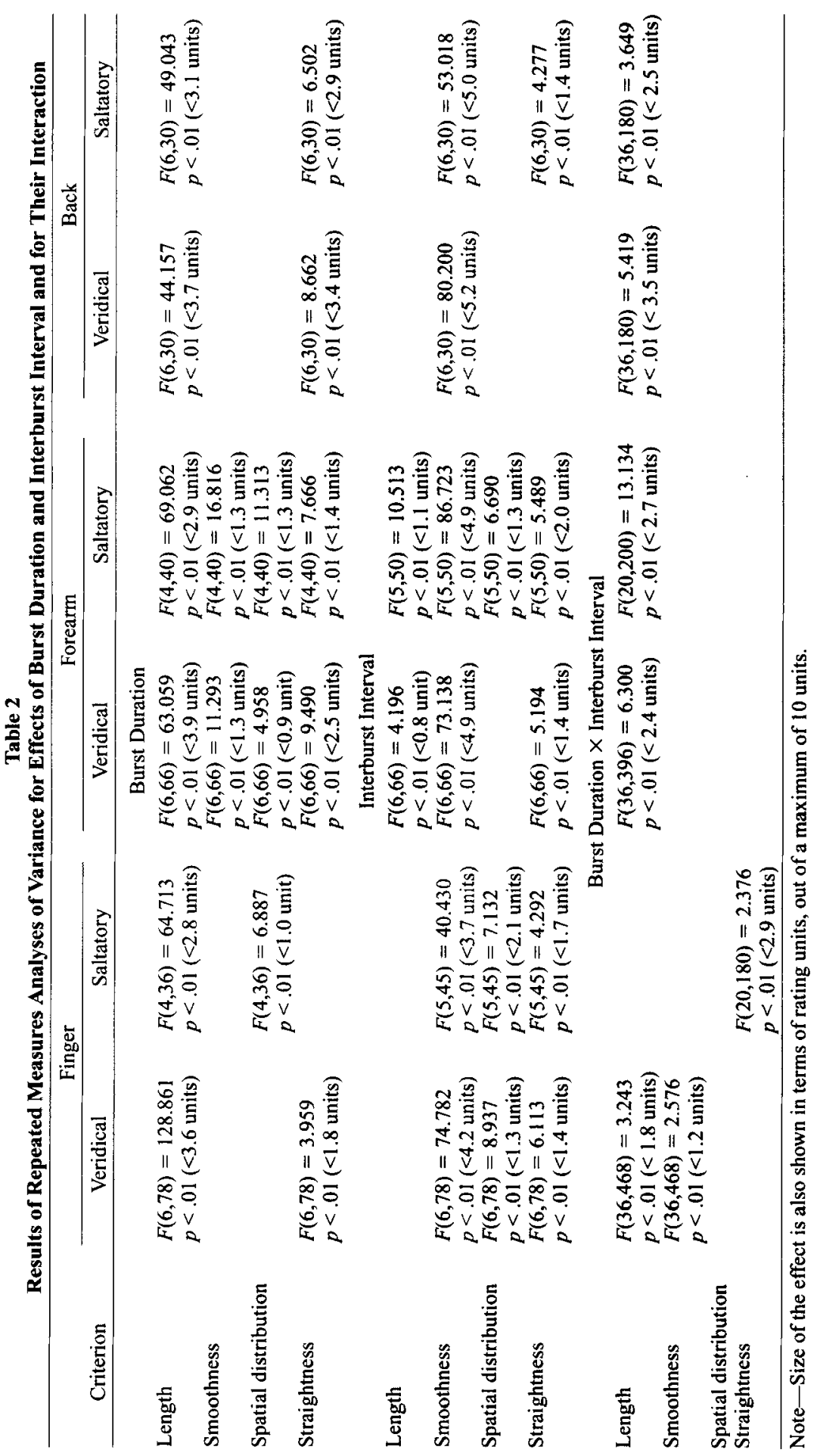


bution $[F(4,36)=6.009, p<.01$, less than 1 unit]. Interactions were also found between mode and IBI on the forearm for smoothness $[F(5,45)=3.355, p<.05$, less than 1 unit] and on the back for spatial distribution $[F(6,30)=4.015, p<.01$, less than 1 unit $]$. Again, these were considered to be minor effects, given the full range of potential responses.

\section{Discussion}

The data from single characteristics indicate that there exist sets of timing parameters that produce lines judged as "good" for both modes at each site. But the particular range of parameters that produces the best judgments (the lightest shades in Figures 3 and 4) depends on the quality judged, as well as on the site. For example, perceived length was optimal for longer BDs at all IBIs. At the shorter BDs and short IBIs, perceived length dropped off dramatically. In the case of straightness, on the other hand, judgments were uniformly good, except at the longest BDs (seen in Figure 4). Similar inconsistencies were seen for the other judged qualities. Certainly, all of the qualities are important for appreciation of a "good" line, but there does not appear to be a single set of spatiotemporal parameters that can be used to generate the best ratings for each characteristic. For a particular application, it might be appropriate to select stimulus parameters so as to optimize one quality or another. For example, whereas the smoothest lines are generated with combinations of the smallest durations, the longest lines require the longer durations. These results can be summarized as follows.

Length. All three sites follow the same pattern: Judgments of length increased with BD. Although there was no consistent main effect of IBI, in most cases there was a significant interaction of IBI with BD, in that stimuli having longer IBIs were judged to be longer for a given BD. There was no significant effect of mode.

Smoothness. Smoothness judgments were primarily a function of IBI: The shorter the IBI, the smoother the stimulus was judged to be. There were significant effects of $\mathrm{BD}$ on the forearm for both modes, so that the lines felt smoother at the extremes and less so at intermediate levels (note the double-headed arrows in the figures). There was no significant effect of mode.

Spatial distribution. Perceived spatial distribution was generally good for all conditions and improved when lines were drawn with short IBIs and with short and midrange BDs, but the results were not as consistent as those for length or smoothness. There was no significant effect of presentation mode.

Straightness. Shorter BDs and shorter IBIs produced the sensation of straighter lines. There was no significant effect of mode.

To return to a rate-related issue raised earlier, it was suggested that certain aspects of tactually (or even visually) drawn lines might only appear within limited ranges of velocity. Two extreme examples were given: If the ve- locity was too great, overall perceived length of a sensation could be foreshortened (Essick, 1991), whereas with slower velocities, lines appear to wander from a straight path (Langford et al., 1973). In order to explore these effects in the present data, the velocities of the presentations were calculated for the maximum length of each array and over all combinations of BDs and IBIs. The duration of a presentation was calculated as the sum of seven BDs and six IBIs for each of these combinations. Although the same temporal parameters were used on all the body sites, two ranges of velocity are represented in these data because of the difference in traverse length on the arrays. These ranges are shown in Table 1. There is a small region in the table in which the velocities of the Optacon and the Princeton Linear Arrays overlap, indicated by the highlighted cells. These are also shown in Figure 4 by the dashed rectangles in the data fields for the quality of length (and apply to all qualities at a site). Note that judgment levels in the common velocity regions over the two array sizes were very different, indicating that velocity alone did not determine sensation magnitude. Rather, qualities depended on the levels of the specific parameters of either BD or IBI, as is shown by the statistical analyses.

Panels A and B in Figure 5 show the overall relationship between velocity and length judgments for the arm. For both saltatory and veridical conditions, the relationship between perceived length and velocity was relatively consistent over the ranges available in this series. As velocity increased, perceived length became smaller, consistent with the upper range of Essick's (1991) data. Similarly, panels C and D indicate that the straightness of a "drawn" line on the arm is directly related to velocity, over a range inclusive of that examined by Langford et al. (1973). These figures are typical of the results when the back was stimulated and, except for the range shift, also represent well the results from the finger. Of course, because all of the stimuli at a site were generated over the same physical distance, there is a consistent relationship between the velocity of the perceived movement and the BD and IBI. For example, the effect of velocity on perceived length is certainly related to the significant main effect of BD, shown in Figures 3 and 4, in which the rating of length for both pattern generation modes decreased with BD. When straightness was judged, both BD and IBI influenced the judgments.

In addition, recall that the same array was used on the back and on the arm. Despite the known differences in several measures of spatial sensitivity (Stevens, 1990; Weinstein, 1968; Wilska, 1954) and cortical representation (Sur, Merzenich, \& Kaas, 1980, in primates) between these two sites (presumably reflecting differences in receptor density), it is remarkable that the optimal temporal parameters were essentially identical between these two (as well as with the finger). These data suggest that (1) characteristics of the peripheral sensory system are less important in these judgments than one might have expected and (2) a display presenting such stimuli to one 

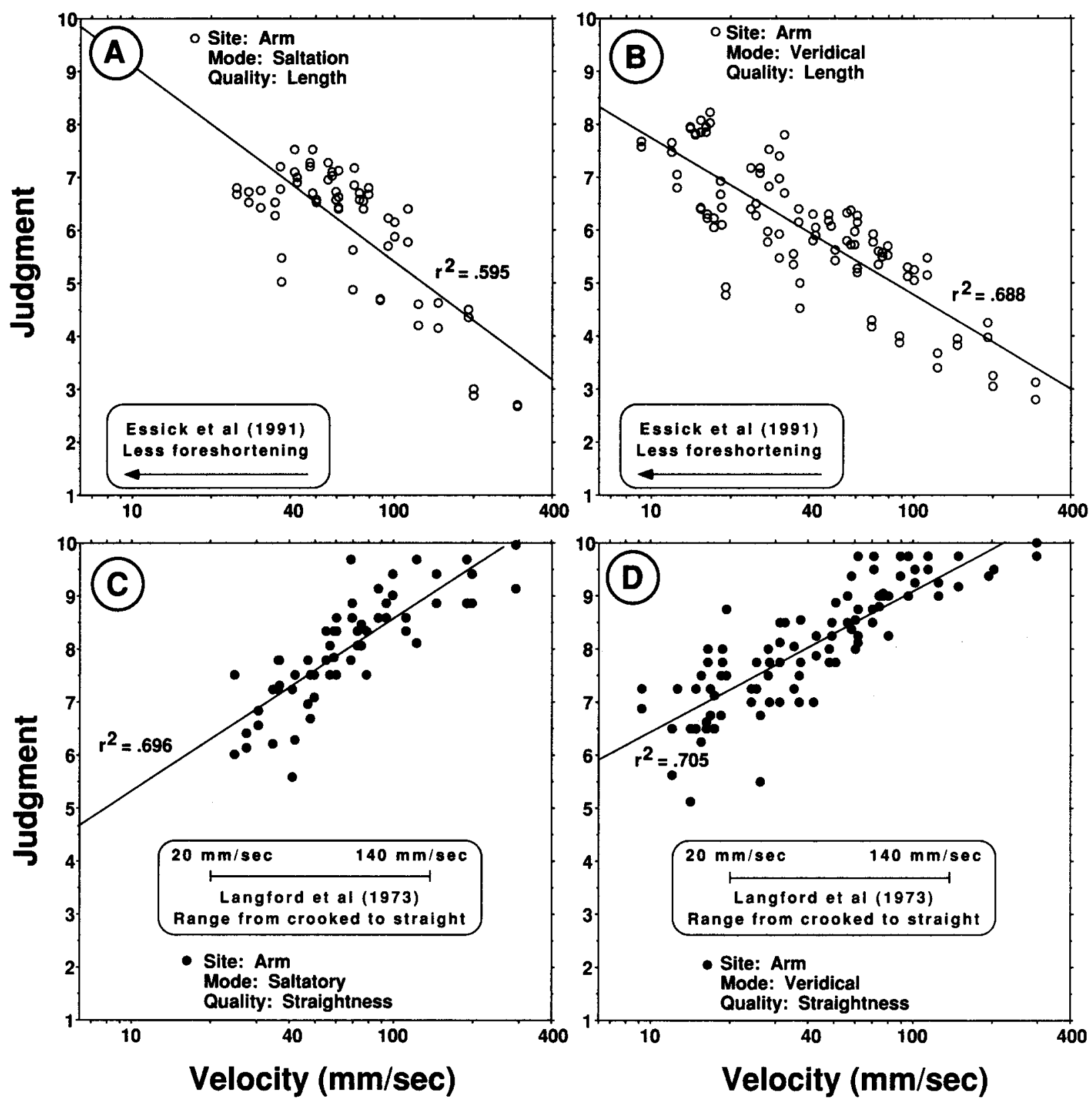

Figure 5. The scattergrams plot the judgments for length and straightness as a function of velocity for the two presentation modes on the forearm. Best-fit lines are included with regression coefficients indicating the goodness-of-fit.

body site could be used on other not-too-dissimilar sites with a strong likelihood that the relationships among stimulus parameters and perceived qualities will be maintained.

Finally, the potential utility of the saltatory mode in applied situations, described earlier, is supported by the comparisons against the veridical presentation mode. Specifically, it appears as though stimuli generated with saltation can substitute for veridical presentations: These data indicate that lines generated with identical BD and IBI parameters in the two modes produce equivalent sensations when these qualities are the bases for judgment.

\section{EXPERIMENT 2}

The results from Experiment 1 strongly suggest that, when "drawing" lines on several body sites, the same stimulus parameters used with two different presentation modes produce similar sensations. However, these stim- 
uli were judged only in the context of other patterns drawn with the same generation mode. Of particular significance is the question of whether the two modes produce discriminable sensations. A more rigorous test of the similarity between the saltatory and the veridical modes is to directly consider them within a paired-comparison paradigm. Experiment 2 incorporated two such paradigms. The first part of the experiment involved discrimination between lines drawn in these two different ways. This is a challenging test of similarity, because observers can use any number of perceptual cues to distinguish between patterns (including those that the experimenter intends to be relevant!). However, one cannot tell which mode is preferred by this method, but only whether they felt different. In the second part, the subjects were presented with pairs of lines generated in the two different modes and were required to identify which was "better." This experiment again addressed the question: What are the characteristics that constitute a "good" line?

\section{Method}

Subjects. Five experienced subjects participated (4 female, 1 male), all of whom served in Experiment 1 as well.

Procedure. Vibrotactile lines generated with the apparatus and parameters described in the General Method section were employed in these studies. Given the similarity in the qualitative judgments over the different body sites tested in Experiment 1, the back was the only site tested with the expectation that the data would be representative of the other sites. In the first part of the experiment, the subjects were required to judge whether the sensations produced by a pair of stimuli were felt to be the same or different. In fact, in half of the trials the modes of generation (the spatial elaboration of the patterns) were the same, and in half they were different. That is, the two stimuli were both generated with the veridical mode or both generated with the saltatory mode (same patterns), or the members of the pair were generated by the two different modes (different patterns). In the second part, the subjects were required to identify which of a pair of sensations was the "better" line. In each of these trials, the presentation modes for the two stimuli were always different: One of the lines was generated with the veridical mode, whereas the other was generated with the saltatory mode.

In each part of the experiment, there were two sessions: One in which the observers judged lines generated "up" the back, and a second in which the lines were generated "down." This separation of directions was done to minimize confusion as to where to direct attention at the beginning of each trial. Each session consisted of four identical blocks of trials, in which two stimuli were presented. Stimulus pairs were generated with identical temporal parameters chosen from the full range of BDs and IBIs (4-139 msec) used in Experiment 1 , so the total pattern duration was the same for each token and only the spatial layout differed. When all the possible pairings of the levels of BDs and IBIs are enumerated, there are 42 pairs in which the members are different and 7 in which they are the same. In order to ensure equal probabilities for same versus different judgments in the first part, the 42 different pairs were randomly presented with an equal number of same pairs in each block of trials (by repeating each of the same pairs six times in the series). In the second part, only the different pairs were presented.

At the beginning of each session, the observers were instructed as to their task: in the first part of the experiment, to discriminate between the two lines, in the second part, to identify the "best" line, based on the criteria from Experiment 1, that appeared to capture the essence of a vector in a tactile display. With a keystroke, the observer initiated each trial, which consisted of a brief preparatory delay, the first presentation, a 5-sec delay, and then the second presentation. The subject reported responses on an appropriately marked two-button keyboard: same or different in the first part or first or

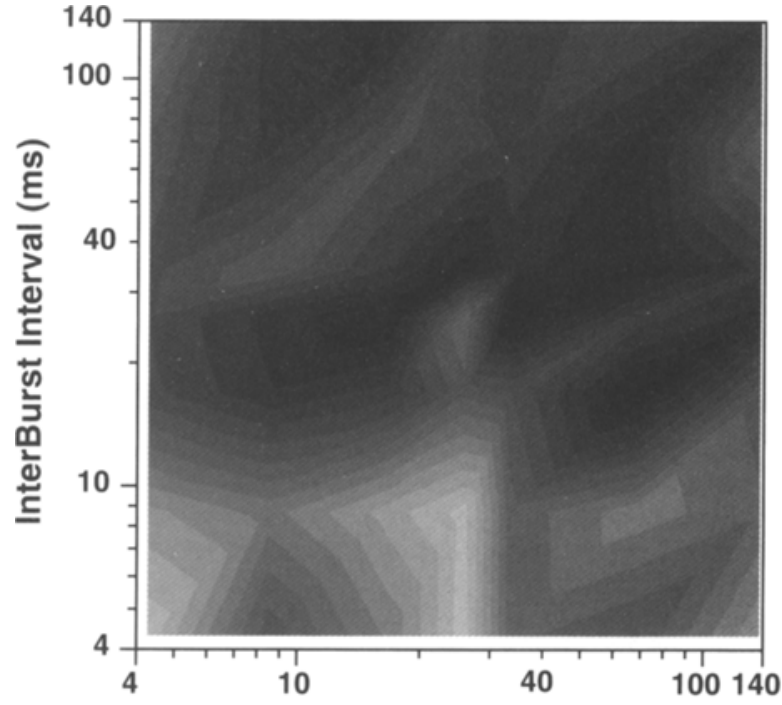

Burst Duration (ms)
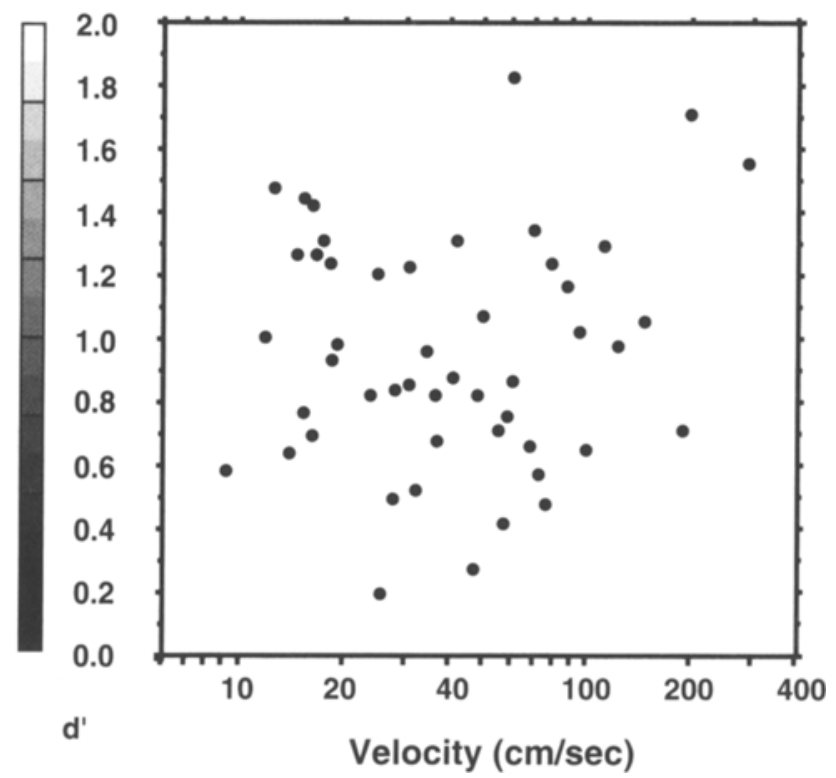

Figure 6. The results from the first paired comparison in the first part of Experiment 2 are shown in a manner similar to those for Experiment 1. The statistic $d^{\prime}$ is plotted for each combination of burst duration and interburst interval in the left panel. The lighter the region, the more often was the pair correctly discriminated. These data are also shown as a function of velocity in the right panel. The actual values of $d^{\prime}$ ranged from 0.08 to 1.45 . 
second in the second part. In the discrimination study, auditory feedback was provided, indicating the accuracy of each response.

\section{Results and Discussion}

For the first part of the experiment, when identical stimuli were presented, the majority $(82 \%)$ of the responses were correct. Of greater interest is the performance when both a veridical line and a saltatory line were paired. Were subjects able to reliably discern that two different stimuli were presented, or did the stimuli feel the same? In fact, when the stimuli were presented in the two different modes, observers responded same the majority of the time: More than $63 \%$ of the responses to these stimuli were incorrect. The difference between $p$ (same $\mid$ same) (hits $=82 \%$ ) and $p$ (same $\mid$ different) (false alarms $=63 \%$ ) was found to be significant $[F(1,4)=16.617, p<.05]$, but the agreement between the two values is remarkable, underscoring the similarity in sensations. Given that performance was not $100 \%$ correct when identical stimuli were paired, it was deemed important to capture both hit and false alarm rates for each condition. A statistic from signal detection theory, $d^{\prime}$, was calculated from these two values (Swets, 1964). The data were transformed into this measure of discriminability and are plotted in Figure 6 . The first panel shows $d^{\prime}$ as a function of the BD $\times$ IBI condition in a manner similar to Figures 3 and 4. Examination of the figure reveals that discriminability was generally poor. The critical value for $75 \%$ correct is 1.35 , and high levels of discriminability usually result in $d^{\prime}$ values of 2 to 3 . It is certainly possible that with more experience with this task, subjects might be able to improve their ability to distinguish between these modes, but the emphasis here is on intuitive displays that can be used without extensive training. There was a significant main effect of IBI on accuracy in this task $[F(6,24)=5.003$, $p<.05]$. Note that the shading is lighter gray in the lower region of the graph, where $d^{\prime}$ approaches the value 1.45 for some conditions. What is somewhat surprising is that the region of highest discriminability was that for the shortest temporal separations between bursts, yet appears to be in the midrange of vibratory BDs. It is not obvious why it is in this range that the saltatory stimulus felt less like the veridical stimulus. It is worth noting that a comparison of the data in Figures 3 and 4 from Experiment 1, when stimuli were judged on the back, show that the more obvious differences between the veridical and the saltatory judgments for smoothness, spatial distribution, and straightness occurred in the same BD $\times$ IBI region of Figure 6 as that at which the highest levels of $d^{\prime}$ were found. In summary, these data indicate that when the two modes were compared directly, saltatory presentations created sensations that were indistinguishable from those produced by the veridical mode over a large region of the $\mathrm{BD} \times$ IBI space explored here. It is likely that one could either increase or decrease the discriminability of the pair by manipulating the temporal parameters of the members in a trial, but the apparent correspondence between sensations shown here is so compelling that, in practice, stimuli presented in the two modes could be readily substituted for one another. The second graph in Figure 6 allows another view of these data, illustrating the independence of the judgments from velocity over the range described in the first panel.

The judgments made in the second part of the experiment were numerically encoded: When the saltatory stimulus was chosen as "best," a score of 0.00 was recorded, whereas 1.00 was entered if the veridical was preferred. The proportions of preferences are plotted in Figure 7.
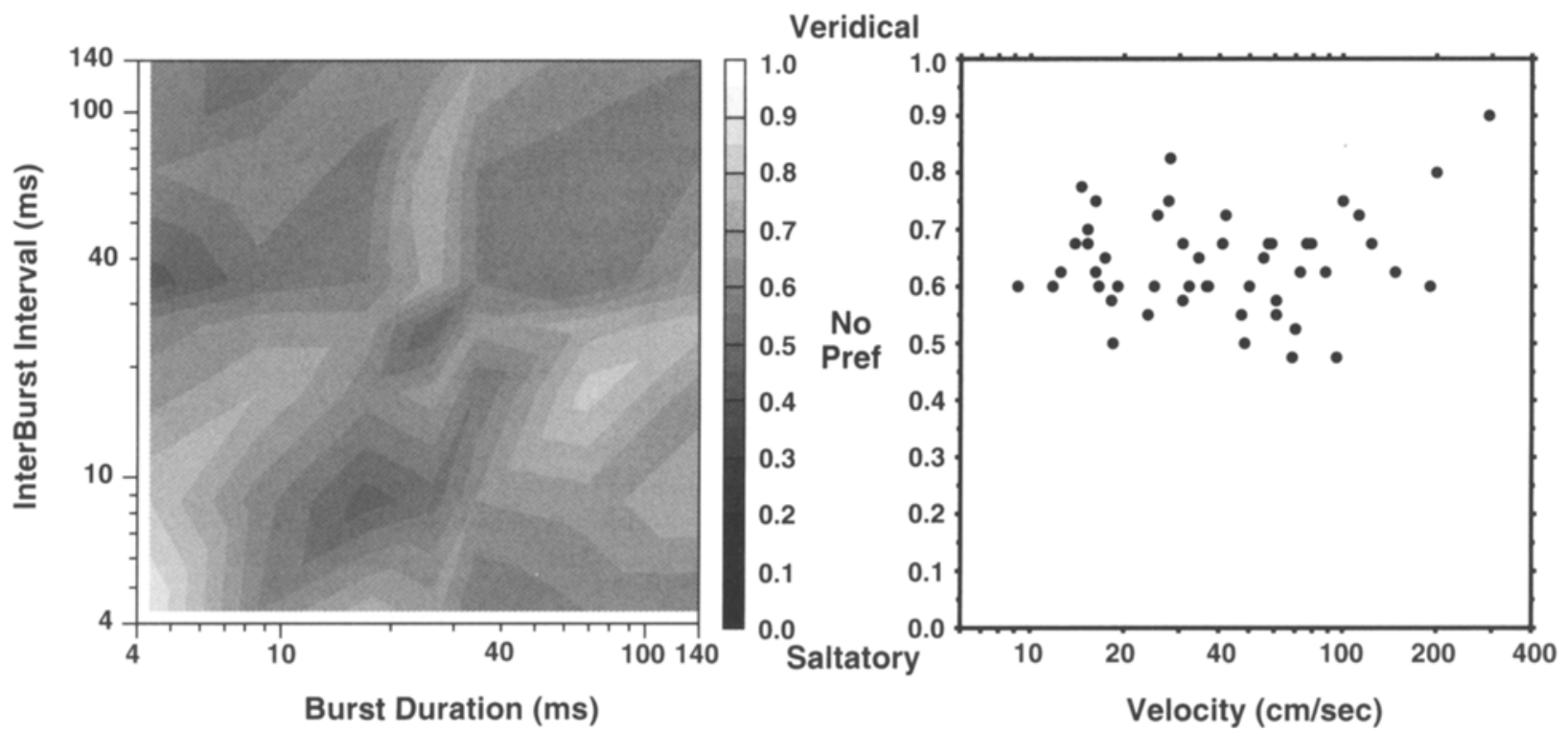

Figure 7. The results from the second part of Experiment 2, shown as in Experiment 1. Plotted in the left panel is the proportion of ratings for each set of temporal conditions in which a preference was shown for the veridical over the saltatory pattern within a pairedcomparison trial. The lighter or darker an area, the stronger a preference for one or the other mode, as is shown in the legend. These data are also shown as a function of velocity in the right panel. Actual values ranged from 0.35 to 0.90 . 
The first panel is in terms of BD and IBI, whereas the second panel plots the proportions as a function of velocity. If the two stimuli within each trial felt the same, judgments in this forced-choice paradigm should be randomly distributed over trials between the two modes (resulting in a value of 0.5 ). In fact, the mean of the judgments was 0.641 , suggesting a slight propensity to judge the veridical presentations as "better." However, chi-square analysis indicated that there was no significant difference between the data set and one having a mean of 0.5 [no preference; $\chi^{2}(2, N=5)=4.818, p=.09$ ]. From Figure 7 , there does not appear to be any consistent pattern of performance related to $\mathrm{BD}$ and IBI levels or to the extensive range of velocity. A repeated-measures ANOVA confirms this observation: There were no main effects of $\mathrm{BD}$ or IBI. The absence of a strong preference for one presentation mode over the other further supports the equivalence of the sensations produced by these two over the majority of the temporal conditions tested.

\section{GENERAL DISCUSSION}

Taken as a whole, the data from these experiments indicate that there is a strong equivalence of the two presentation modes within the temporal parameters examined. Judgments of perceived length, smoothness, straightness, and even spatial distribution were very similar for the two modes and were influenced in the same ways by timing parameters. A question could be raised as to whether these qualities are independent of one another. Although the present experiments were not designed to address this question specifically, in some instances the data are suggestive. For example, judgments of perceived length and smoothness were somewhat orthogonal to one another (in Figures 3 and 4), depending primarily on BD in the first case and on IBI in the second. But both perceived smoothness and spatial distribution generally improved as IBI decreased, suggesting a common basis for these judgments. Further work could clarify these issues. In Experiment 1, the mode of line presentation generally did not have a significant effect on the qualities examined, nor were there major interactions between mode and the timing parameters. Given these findings, the lack of a strong effect of BD, IBI, and velocity in Experiment 2 is not surprising. In both parts of Experiment 2, the timing parameters were the same for the two lines in each trial. Thus, since the line qualities depended almost exclusively on variations in the timing parameters, when these were held constant within a paired comparison, with only mode varying, the lines more often than not felt the same.

The results from Experiment 1, in which data were compared among three body sites, indicate that, for the same stimulus conditions, similar sensations were evoked. Given the differences in receptor complement, sensitivity, and spatial acuity over the three sites examined, this finding is remarkable. It is possible that the comparison of judgments across body sites is affected by a shift in the value of the psychological scale. For example, despite the great similarity over sites in the data plotted in Figures 3 and
4 , the ratings of perceived length may represent different perceived extents across sites because judgments depended on the sizes of the arrays. Recall that the instructions to the observers (Experiment 1, Procedure section) directed them to rate the length of the sensation relative to the size of each array. On the other hand, in the cases of smoothness, spatial distribution, and straightness, judgments could be made independent of site or array parameters. What is, perhaps, most relevant is that for each quality, very similar patterns of response were obtained from all three sites, related in the same manner to BD and IBI. Such a correspondence over sites (and even modalities) has been described before in the temporal range required to produce saltatory sensations (Geldard, 1975). Hari (1995; Hari \& Kiesilä, 1996) replicated and extended some of these data to show that auditory saltation occurred over the same ranges of time as tactual saltation (see also Shore, Hall, \& Klein, 1998). These data are particularly interesting because auditory localization requires binaural central nervous system computation, whereas it is likely that tactile localization is based on cortical somatotopic organization (Burton \& Sinclair, 1996, p. 113), so perceived mislocalizations in the two modalities must occur beyond these levels of processing. Although it was not the intent of this paper to define a neural locus for these effects, it is of some interest to note that repetitive presentation of tactile spatiotemporal stimuli like those used here can lead to considerable changes in cortical spatial organization. These have been found in the primary somatosensory cortex (Wang, Merzenich, Sameshima, \& Jenkins, 1995; Whitsel et al., 1989; Wiemer, Spengler, Joublin, Stagge, \& Wacquant, 1998, 2000) and in the secondary somatosensory cortex, an area receiving much interest in cognitive research (Maldjian et al., 1999).

From the perspective of application, the present results could have an important impact on the development of tactile display systems. There have been recent demonstrations in which tactile arrays have been used successfully to present flight information in fixed- and rotarywinged aircraft. Using a linear array on the forearm to present airspeed information and a two-dimensional abdominal display for pitch and roll information, blindfolded aircraft pilots were able to recover from unusual attitudes and to perform simple aerobatics (Mead et al., 1994; Raj, McGrath, Rochlis, Newman, \& Rupert, 1998; Raj, Suri, et al., 1998; Rupert et al., 1993). Consequently, it is clear that different sites can and will continue to be employed for future applications to present spatial orientation and attitude information tactually. The comparisons obtained here demonstrate the utility of two likely presentation modes on likely sites of application. The data also support the possibility of shifting the site of application from one body site to another while maintaining a constant temporal code for a number of qualities. In one example, if a person is to be trained on one site because of instructional convenience, transfer to another body site while maintaining the same temporal parameters for generating the linear stimulus would likely result in an apparently identical sensation, based on the 
qualities explored here. Moreover, the complex surfaces in Figures 3-4 and 6-7 could be used to create a set of parameters that should generate the best vector on the skin to optimize any of several particular sensation qualities.

Finally, it was shown that directional information may be displayed most efficiently on a tactile interface by taking advantage of sensory saltation. By demonstrating that saltation could accurately duplicate the sensation produced by the veridical mode, a savings in equipment could be realized, since fewer tactors are required than are needed in other modes, and/or the mode could be utilized in a fault tree, in case tactors fail in a dense display, if tactor cost is not an issue. One model of tactile pattern perception likens the skin to blurred vision (Loomis, 1990) by hypothesizing that the skin cannot resolve stimuli located close together, because it acts like a low-pass filter for spatial detail. Through the manipulation of only the temporal parameters of a stimulus, the saltatory presentation mode can effectively increase the resolution of a device, providing a higher density sensation than might be expected given the actual number of loci stimulated. For the practical reasons of hardware efficiency (or redundancy), these findings show that an array having a coarse resolution could be used to present fine detail, or alternatively, a larger number of tactors could be available to replace those that might fail in hostile environments. Although judgments involving relatively complex vibrotactile patterns can often be made without regard to fine spatial details of the stimuli, it is likely that an appreciation of the position, orientation, and extent of the stimulus on the array will be necessary to correctly perceive stimuli encoding body orientation in space.

\section{REFERENCES}

Bliss, J. C., Katcher, M. H., Rogers, C. H., \& Shepard, R. P. (1970). Optical-to-tactile image conversion for the blind. IEEE Transactions on Man-Machine Systems, MMS-11, 58-64.

Bolanowski, S. J., Gescheider, G. A., \& Verrillo, R. T. (1994). Hairy skin: Psychophysical channels and their physiological substrates. Somatosensory \& Motor Research, 11, 279-290.

Bolanowski, S. J., Gescheider, G. A., Verrillo, R. T., \& CheckOSKY, C. M. (1988). Four channels mediate the mechanical aspects of touch. Journal of the Acoustical Society of America, 84, 1680-1694.

Brooks, P. L., Frost, B. J., Mason, J. L., \& Gibson, D. M. (1986). Continuing evaluation of the Queen's University tactile vocoder: II. Identification of open-set sentences and tracking narrative. Journal of Rehabilitation Research \& Development, 23, 129-138.

BURTON, H., \& SinCl.AIR, R. (1996). Somatosensory cortex and tactile perceptions. In L. Kruger (Ed.), Pain and touch (2nd ed., pp. 105177). San Diego: Academic Press.

Cholewiak, R. W. (1976). Satiation in cutaneous saltation. Sensory Processes, 1, 163-175.

CHOLEWIAK, R. W. (1986, May). The perception of tactile distance: Influences of body site, space, and time. Paper presented at the 111th Meeting of the Acoustical Society of America, Cleveland.

CHOLEWIAK, R. W. (1999). The perception of tactile distance: Influences of body site, space, and time. Perception, 28, 851-875.

Cholewiak, R. W., \& Collins, A. A. (1988). Vibrotactile pattern recognition, discrimination, and masking. In C. E. Sherrick \& R. W. Cholewiak (Eds.), Princeton cutaneous research project report No. 51 (pp. 4-10). Princeton, NJ: Princeton University, Department of Psychology.

Cholewiak, R. W., \& Collins, A. A. (1991). Sensory and physiolog- ical bases of touch. In M. A. Heller \& W. Schiff(Eds.), The psychology of touch (pp. 23-60). Hillsdale, NJ: Erlbaum.

Cholewiak, R. W., \& Collins, A. A. (1995). Vibrotactile pattern discrimination and communality at several body sites. Perception \& Psychophysics, 57, 724-737.

Cholewiak, R. W., \& Craig, J. C. (1984). Vibrotactile pattern recognition and discrimination at several body sites. Perception \& Psychophysics, 35, 503-514.

Costanzo, R. M., \& Gardner, E. P. (1980). A quantitative analysis of responses of direction-sensitive neurons in somatosensory cortex in awake monkeys. Journal of Neurophysiology, 43, 1319-1341.

CraIG, J. C. (1980). Modes of vibrotactile pattern generation. Journal of Experimental Psychology: Human Perception \& Performance, 6 , $151-166$.

Craig, J. C., \& Sherrick, C. E. (1982). Dynamic tactile displays. In W. Schiff \& E. Foulke (Eds.), Tactual perception: A sourcebook (pp. 209-233). Cambridge: Cambridge University Press.

DALEY, M. L., \& Singer, M. (1975). A spatial resolution measure of cutaneous vision. IEEE Transactions on Systems, Man, \& Cybernetics, 16, 124-125.

Darian-Smith, I. A. (1982). Touch in primates. In M. Rosenzweig \& L. W. Porter (Eds.), Annual review of psychology (Vol. 33, pp. 155194). Palo Alto, CA: Annual Reviews.

Engelmann, S., \& Rosov, R. J. (1975). Tactual hearing experiment with deaf and hearing subjects. Journal of the Exceptional Child, 41, 245-253.

EssicK, G. K. (1991). Human capacity to process directional information provided by tactile stimuli which move across the skin: Characterization and potential neural mechanisms. In O. Franzen \& J. Westman (Eds.), Information processing in the somatosensory system (Wenner-Gren Center International Symposium Series, Vol. 57, pp. 329-339). New York: Macmillan.

ExNER, S. (1875). Über das Sehen von Bewegung und die Theorie des zusammengesetzten Auges. [On the perception of motion and the theory of binocular vision.] Sitzungsberichte der Akademie der Wissenschaften, 72, 156-190.

Gardner, E. P., \& Palmer, C. I. (1990). Simulation of motion on the skin: III. Mechanisms used by rapidly adapting cutaneous mechanoreceptors in the primate hand for spatiotemporal resolution and twopoint discrimination. Journal of Neurophysiology, 63, 841-859.

GARDNER, E. P., \& SKLAR, B. F. (1994). Discrimination of the direction of motion on the human hand: A psychophysical study of stimulation parameters. Journal of Neurophysiology, 71, 2414-2429.

GELDARD, F. A. (1975). Sensory saltation: Metastability in the perceptual world. Hillsdale, NJ: Eribaum.

Geldard, F. A., \& Sherrick, C. E. (1972). The cutaneous "rabbit": A perceptual illusion. Science, 178, 178-179.

Geldard, F. A., \& Sherrick, C. E. (1983). The cutaneous saltatory area and its presumed neural basis. Perception \& Psychophysics, 33, 299-304.

Geldard, F. A., \& Sherrick, C. E. (1986, July). Space, time and touch. Scientific American, 255, 91-95.

Gonzales, G. R. (1996). Symbol recognition produced by points of tactile stimulation: The illusion of linear continuity. Mayo Clinic Proceedings, 71, 1039-1046.

Graham, C. H. (1951). Visual perception. In S. S. Stevens (Ed.), Handbook of experimental psychology (pp. 868-920). New York: Wiley.

Graham, C. H. (1965). Perception of movement. In C. Graham, N. Bartlett, J. Brown, C. G. Mueller, \& L. Riggs (Eds.), Vision and visual perception (pp. 575-588). New York: Wiley.

Greenspan, J. D., \& Bolanowski, S. J. (1996). The psychophysics of tactile perception and its peripheral physiological basis. In L. Kruger (Ed.), Pain and touch (2nd ed., pp. 25-104). San Diego: Academic Press.

HARI, R. (1995). Illusory directional hearing in humans. Neuroscience Letters, 189, 29-30.

HARI, R., \& KIESIL ̈̈, P. (1996). Deficit of temporal auditory processing in dyslexic adults. Neuroscience Letters, 205, 138-140.

Hollins, M., Faldowski, R., Rao, S., \& Young, F. (1993). Perceptual dimensions of tactile surface texture: A multidimensional scaling analysis. Perception \& Psychophysics, 54, 697-705. 
JoHnSON, K. O., \& HsiaO, S. S. (1992). Neural mechanisms of tactual form and texture perception. Annual Review of Neuroscience, 15 227-250.

Johnson, K. O., Van Boven, R. W., \& Hsiao, S. S. (1993). The perception of two points is not the spatial resolution threshold. In J. Boivie, P. Hansson, \& U. Lindblom (Eds.), Touch, temperature, and pain in health and disease: Mechanisms and assessments (Wenner-Gren Center International Symposium Series: Progress in Pain Research and Management, Vol. 3, pp. 389-403). Seattle: IASP Press.

KENKEL, F. (1913). Untersuchungen über den Zusammenhang zwischen Erscheinungsgrösse und Erscheinungsbewegung bei einigen sogenannten optischen Täuschungen. [Investigations of the relationship between apparent size and apparent motion in the case of some socalled optical illusions.] Zeitschrift für Psychologie, 67, 358-449.

KIRMAN, J. H. (1974). Tactile apparent movement: The effects of interstimulus onset interval and stimulus duration. Perception \& Psychophysics, 15, 1-6.

KIRMAN, J. H. (1975). The effect of number of stimulators on the optimal interstimulus onset interval in tactile apparent movement. Perception \& Psychophysics, 17, 263-267.

KORTE, A. (1915). Kinernatoskopische Untersuchungen. [Cinematoscopic investigations.] Zeitschrift für Psychologie, 72, 193-296.

Korteling, J. E., \& van Emmerik, M. L. (1998). Continuous haptic information in target tracking from a moving platform. Human Factors, 40, 198-208.

LANGFord, N., Halt, R. J., \& Monty, R. A. (1973). Cutaneous perception of a track produced by a moving point across the skin. Journal of Experimental Psychology, 97, 59-63.

Loomis, J. M. (1974). Tactile letter recognition under different modes of stimulus presentation. Perception \& Psychophysics, 16, 401-408.

Loomis, J. M. (1990). A model of character recognition and legibility. Journal of Experimental Psychology: Human Perception \& Performance, 16, 106-120.

Maldjian, J. A., Gottschalk, A., Patel, R. S., Pincus, D., Detre, D., \& ALsoP, D. (1999). Mapping of secondary somatosensory cortex activation induced by vibrational stimulation: An fMRI study. Brain Research, 824, 291-295.

MEAD, A. M., RuperT, A. H., \& JaRMul, E. S. (1994, June). A tactile interface for virtual and dynamic environments. Paper presented at the Image VII Conference, Tucson.

Naval Aerospace Medical Research Laboratories (1996). A tactile interface to improve situational awareness [Videotape]. Pensacola, FL: Author.

Neuhaus, W. (1930). Experimentelle Untersuchung der Scheinbewegung. [Experimentai investigations of motion perception.] Archiv für die Gesamte Psychologie, 75, 315-458.

Oller, D. K., \& Ellers, R. E. (1987). Tactual artificial hearing for the deaf. In F. Bess (Ed.), Hearing impairment in children (pp. 310-328). Parkton, MD: York Press.

PENDERS, H. J. (1953). Perception of apparent motion induced by touch. Nieuwe Reeks, 16, 1-22.

Raj, A. K., McGrath, B. J., Rochlis, J., Newman, D., \& Rupert, A. H. (1998, June). The application of tactile cues to enhance situation displays. Paper presented at the Third Annual Symposium on Situational Awareness in the Tactical Air Environment, Patuxent River, MD.

Raj, A. K., Suri, N., Braithwaite, M. G., \& Rupert, A. H. (1998, October). The tactile situation awareness system in rotary wing aircraft: Flight test results. Paper presented at the RTA/HFM Symposium on Current Aeromedical Issues in Rotary Wing Operations, San Diego.

RobBins, A. M., Hesketh, L. J., \& Bivins, C. (1993). Tactaid 7 reference guide and orientation. Somerville, MA: Audiological Engineering Corp.

Rupert, A. H., Guedry, F. E., \& ReschKe, M. F. (1993, October). The use of a tactile interface to convey position and motion perceptions. Paper presented at the NATO Advisory Group for Aerospace Research and Development (AGARD), Lisbon.

SAUNDERS, F. A. (1974). Electrocutaneous displays. In F. A. Geldard (Ed.), Cutaneous communication systems and devices (pp. 20-26). Austin, TX: Psychonomic Society
Schneider, S. L., Hughes, B., Epstein, W., \& BaCh-Y-Rita, P. (1986). The detection of length and orientation changes in dynamic vibrotactile patterns. Perception \& Psychophysics, 40, 290-300.

Sherrick, C. E., \& Cholewiak, R. W. (1977, May). Matching speech to vision and touch. Paper presented at the Conference for Speech Analyzing Aids for the Deaf, Gallaudet College, Washington, DC.

Sherrick, C. E., \& Rogers, R. (1966). Apparent haptic movement. Perception \& Psychophysics, 1, 175-180.

SHORE, D. I., HALL, S. E., \& KLEIN, R. M. (1998). Auditory saitation: A new measure for an old illusion. Journal of the Acoustical Society of America, 103, 3730-3733.

SPARKS, D. W. (1979). The identification of the direction of electrocutaneous stimulation along lineal multistimulator arrays. Perception \& Psychophysics, 25, 80-87.

Stevens, J. C. (1990). Perceived roughness as a function of body locus. Perception \& Psychophysics, 47, 298-304.

Stevens, J. C., \& Choo, K. K. (1996). Spatial acuity of the body surface over the life span. Somatosensory \& Motor Research, 13, 153-166.

Strybel, T. Z., SPAN, S. A., \& WitTY, A. M. (1998). The effect of timing and spatial separation on the velocity of auditory apparent motion. Perception \& Psychophysics, 60, 1441-1451.

Sur, M., Merzenich, M. M., \& KaAs, J. H. (1980). Magnification, receptive-field area, and "hypercolumn" size in Areas 3 b and 1 of somatosensory cortex in owl monkeys. Journal of Neurophysiology, 44, 295-311.

SwETS, J. A. (ED.) (1964). Signal detection and recognition by human observers. New York: Wiley.

VAlLbo, Å. B., \& Johansson, R. S. (1978). The tactile sensory innervation of the glabrous skin of the human hand. In G. Gordon (Ed.), Active touch: The mechanisms of recognition of objects by manipulation. A multidiscipinary approach (pp. 29-54). Oxford: Pergamon.

VERRILLO, R. T. (1974). Vibrotactile intensity scaling at several body sites. In F. A. Geldard (Ed.), Cutaneous communication systems and devices (pp. 9-14). Austin, TX: Psychonomic Society.

WanG, X., Merzenich, M. M., Sameshima, K., \& Jenkins, W. (1995) Remodeling of hand representation in adult cortex determined by timing of tactile stimulation. Nature, 378, 71-75.

WEINSTEIN, S. (1968). Intensive and extensive aspects of tactile sensitivity as a function of body part, sex, and laterality. In D. Kenshalo (Ed.), The skin senses (pp. 195-222). Springfield, IL: Thomas.

Weisenberger, J. M., \& Percy, M. E. (1995). The transmission of phoneme-level information by multichannel tactile speech perception aids. Ear \& Hearing, 16, 392-406.

Werthermer, M. (1912). Experimentelle Studien über das Sehen von Bewegung. [Experimental studies on the perception of motion.] Zeitscrift für P $P_{\text {sychologie, 61, 161-265. }}$

Whitsel, B. L., Favorov, O. V., Tommerdahl, M., Diamond, M. E., Juliano, S. L., \& Kelly, D. G. (1989). Dynamic processes governing the somatosensory cortical response to natural stimulation. In J. S. Lund (Ed.), Sensory processing in the mammalian brain (pp. 84116). New York: Oxford University Press.

Whitsel, B. L., Franzen, O., Dreyer, D. A., Hollins, M., YounG, M., Essick, G. K., \& Wong, C. (1986). Dependence of subjective traverse length on velocity of moving tactile stimuli. Somatosensory Research, 3, 185-196.

Wiemer, J., Spengler, F., Joublin, F, Stagge, P., \& Wacquant, S. (1998). A model of cortical plasticity based on temporal integration and segregation. In N. Elsner \& H. Schnitzler (Eds.), Proceedings of the 26th Göttingen Neurobiology Conference (pp. 763-768). Stuttgart: Thieme.

Wiemer, J., Spengler, F., Joublin, F., Stagge, P., \& Wacquant, S. (2000). Learning cortical topography from spatiotemporal stimuli. Biological Cybernetics, 82, 173-187.

WILSKA, A. (1954). On the vibrational sensitivity in different regions of the body surface. Acta Physiologica Scandinavica, 31, 285-289.

(Manuscript received May 3, 1999; revision accepted for publication November $5,1999$. 